\title{
Changes in Cerebral Oxygen Saturation and Blood Flow During Hypoxic Gas Ventilation Therapy in HLHS and CoA/IAA Complex With Markedly Increased Pulmonary Blood Flow
}

\author{
Kentaro Toiyama, MD; Kenji Hamaoka, MD; Tatsujiro Oka, MD; Naho Kobayashi, MD; \\ Kanae Noritake, MD; Ryuichi Kato, MD; Yoko Kawai, MD; Seiichiro Ozawa, MD; \\ Masashi Nishida, MD; Toshiyuki Itoi, MD
}

\begin{abstract}
Background: Hypoxic gas ventilation therapy has recently been performed to prevent post-birth increased pulmonary blood flow in cases of congenital heart diseases with increased pulmonary blood flow. However, how the oxygen supply to the tissues changes during breathing a hypoxic gas mixture, remains unknown. The changes in cerebral oxygen saturation and blood supply during hypoxic gas ventilation therapy using a nitrogen gas mixture were studied.
\end{abstract}

Methods and Results: Cerebral regional oxygen saturation (cerebral $\mathrm{rSO}_{2}$ ) was measured by near-infrared spectroscopy, and changes in middle cerebral artery (MCA) blood flow and an index of vascular resistance (RI) were assessed in 8 consecutive patients having congenital heart diseases with increased pulmonary blood flow. In all patients, urinary volume increased significantly, and the respiratory rate showed a clear decrease. Percutaneous oxygen saturation showed no significant change. The average of cerebral $\mathrm{rSO}_{2}$ was $67.3 \%$ before hypoxic gas ventilation, but increased to $69.4 \%, 69.1 \%$, and $70.7 \%$ within 1,12 , and $24 \mathrm{~h}$ after initiation of treatment, respectively. MCA blood flow significantly increased in the diastolic phase, and RI significantly improved from 0.80 to 0.68 within $12 \mathrm{~h}$ after initiation of therapy.

Conclusions: These results indicate that hypoxic gas ventilation therapy does not decrease cerebral oxygen saturation, but safely improves the cerebral blood supply in cases of congenital heart diseases with increased pulmonary blood flow. (Circ J 2010; 74: 2125-2131)

Key Words: Brain; Congenital heart disease; Hypoxic gas ventilation; Oxygen saturation; Tissue oxygen supply

B ecause it is often difficult to control the preoperative state in hypoplastic left heart syndrome (HLHS), interruption of the aortic arch (IAA) and coarctation of the aorta (CoA) that systemic circulation are dependent on, there is the need for a right-to-left shunt through the patent ductus arteriosus (PDA). Given early diagnosis, such as that obtained using fetal echocardiography, it is possible to avoid ductal shock, particularly with subsequent infusion of prostaglandin-E1. ${ }^{1}$ However, in HLHS, in particular, IAA and $\mathrm{CoA}$ cause a rapid hemodynamic deterioration due to an increase in the pulmonary-to-systemic blood flow ratio after birth, which is caused because of a postnatal physiological decrease in pulmonary arterial resistance. This is because the pulmonary circulation runs in parallel with the systemic circulation via the thick arterial duct. This causes a severe increase of pulmonary blood flow, and the maintenance of systemic circulation becomes difficult rapidly, thereby resulting in a deterioration of the general status of the patient. Therefore, in order to maintain the systemic blood flow in these patients, it is important to maintain a high pulmonary vascular resistance and prevent changes in the pulmonary-tosystemic blood flow ratio as much as possible. ${ }^{2}$ Two methods have been reported to maintain a high pulmonary vascular resistance. One is the artificial induction of hypercapnia by mixing carbon dioxide with inhaled room air, 3,4 and the other is hypoxic gas ventilation therapy using nitrogen gas mixed

Received November 6, 2009; revised manuscript received May 25, 2010; accepted June 3, 2010; released online August 21, 2010 Time for primary review: 38 days

Department of Pediatric Cardiology and Nephrology, Kyoto Prefectural University of Medicine Graduate School of Medical Science, Kyoto, Japan

Mailing address: Kentaro Toiyama, MD, Department of Pediatric Cardiology and Nephrology, Kyoto Prefectural University of Medicine Graduate School of Medical Science, 465 Kajiicho, Kawaramachi-Hirokouji, Kamigyou-ku, Kyoto 602-8566, Japan. E-mail: toy-ken@koto.kpu-m.ac.jp

ISSN-1346-9843 doi:10.1253/circj.CJ-09-0833

All rights are reserved to the Japanese Circulation Society. For permissions, please e-mail: cj@j-circ.or.jp 


\begin{tabular}{|c|c|c|c|c|c|c|c|c|c|}
\hline Case & Diagnosis & $\begin{array}{c}\text { Birth } \\
\text { weight (g) }\end{array}$ & $\begin{array}{c}\text { Gestational } \\
\text { age (W) }\end{array}$ & $\begin{array}{l}\text { Inhalational } \\
\text { method }\end{array}$ & $\begin{array}{l}\mathrm{FiO}_{2} \\
(\%)\end{array}$ & $\begin{array}{l}\text { End } \\
\text { point }\end{array}$ & $\begin{array}{c}\text { Preoperative } \\
\text { status }\end{array}$ & $\begin{array}{l}\text { Surgical } \\
\text { method }\end{array}$ & $\begin{array}{l}\text { Postoperative } \\
\text { course }\end{array}$ \\
\hline 1 & $\begin{array}{c}\text { TA (II-c), hypo arch, } \\
\text { PDA }\end{array}$ & 3,388 & 39 & Transnasal & 17 & Surgery & Stable & $\begin{array}{l}\text { Norwood } \\
\text { (RV-PA) }\end{array}$ & Discharged \\
\hline 2 & $\begin{array}{l}\text { HLHS (AS, MA), } \\
\text { PFO, PDA }\end{array}$ & 2,816 & 38 & Transnasal & 15 & Surgery & Stable & $\begin{array}{l}\text { Norwood } \\
\text { (RV-PA) }\end{array}$ & Discharged \\
\hline 3 & $\begin{array}{l}\text { IAA(A), SAS, AS, } \\
\text { VSD, PDA, ASD }\end{array}$ & 2,854 & 37 & Transnasal & 18 & Surgery & Stable & ICR & Discharged \\
\hline 4 & $\begin{array}{l}\text { TA (II-C), IAA(A), } \\
\text { ASD, PDA }\end{array}$ & 3,244 & 40 & Intubation & 19 & Surgery & Stable & $\mathrm{EAAA}+\mathrm{PAB}$ & Discharged \\
\hline 5 & $\begin{array}{c}\text { CoA, PDA, VSD, } \\
\text { ASD }\end{array}$ & 3,210 & 42 & Transnasal & 19 & Surgery & Stable & ICR & Discharged \\
\hline 6 & $\begin{array}{l}\text { CoA, PDA, VSD, } \\
\text { PFO, MR,TR }\end{array}$ & 2,910 & 39 & Intubation & 19 & Surgery & Stable & ICR & Discharged \\
\hline 7 & $\begin{array}{l}\text { HLHS (AA, MA), } \\
\text { PDA, ASD }\end{array}$ & 3,400 & 38 & Transnasal & 18 & Surgery & Stable & $\begin{array}{l}\text { Norwood } \\
\text { (RV-PA) }\end{array}$ & Discharged \\
\hline 8 & $\begin{array}{c}\mathrm{IAA}(\mathrm{B}), \mathrm{PDA}, \mathrm{PFO} \\
\text { VSD }\end{array}$ & 3,216 & 39 & Transnasal & 18 & Surgery & Stable & ICR & Discharged \\
\hline
\end{tabular}

Although management with an artificial respirator under intubation was conducted in 2 patients, the preoperative circulatory dynamics were stable in all patients. The transition to surgery was smooth.

TA, tricuspid atresia; PDA, patent ductus arteriosus; RV, right ventricle; PA, pulmonary artery; HLHS, hypoplastic left heart syndrome; AS, aortic stenosis; MA, mitral valve atresia; PFO, patent foramen ovale; IAA, interruption of the aortic arch; SAS, sub-aortic stenosis; VSD, ventricular septal defect; ASD, atrial septal defect; ICR, intracardiac repair; EAAA, extended aortic arch anastomosis; PAB, pulmonary artery banding; CoA, coarctation of the aorta; MR, mitral regurgitation; TR, tricuspid regurgitation; AA, aortic valve atresia.

with inhaled room air. ${ }^{5-8}$ The clinical efficacy of these 2 methods has also been reported. In the cases of the abovementioned complex cardiac anomalies, preoperative circulatory management for the initial surgery plays a particularly important role in the success of the surgical operation ${ }^{9}$ hence, the significance of maintaining a high pulmonary vascular resistance has assumed increasing importance in recent years. At our university hospital, stable preoperative management has become possible since the introduction of hypoxic gas ventilation therapy. However, in the past, it was not clear how the oxygen supply to the tissues would change during hypoxic gas ventilation; hence, the safety of this treatment method has not been fully clarified. In order to solve this problem, we studied the change in the ability to transport oxygen to peripheral tissues during hypoxic gas ventilation therapy, and reported that the oxygen supply to the peripheral tissues indirectly increases during hypoxic gas ventilation therapy. ${ }^{9}$ In the present study, changes in cerebral oxygen saturation during the administration of hypoxic gas ventilation therapy were examined to ascertain the changes in oxygenated blood supply to the brain.

\section{Methods}

The study was conducted on 8 consecutive patients (age, 0 120 days; median, 6.5 days) having aortic valve or aortic arch obstruction and ductal dependent systemic circulation who had been admitted to the pediatric intensive care unit of our hospital between April 2006 and January 2008, and who had undergone hypoxic gas ventilation therapy. The clinical diagnoses of the 8 patients were as follows: HLHS $(n=2)$, IAA with ventricular septal defect $(n=2)$, CoA with ventricular septal defect $(n=2)$, tricuspid atresia (TA) with IAA $(n=1)$, and TA with hypoplastic aortic $\operatorname{arch}(n=1)$. The average birth weight was $3,129 \mathrm{~g}$ and the average gestational age was 39.0 weeks. None of the patients showed heterotaxy or complications of other extracardiac malformations. Hypoxic gas ventilation therapy was applied to newborns and nursing infants having cardiac disease associated with increased pul- monary blood flow, and who reequired their pulmonary blood flow to be controlled. When there was an increase in percutaneous oxygen saturation $\left(\mathrm{SpO}_{2}\right)$ caused by an increased pulmonary blood flow and a progressive decrease in urinary volume under $1 \mathrm{ml} \cdot \mathrm{kg}^{-1} \cdot \mathrm{h}^{-1}$, resulting in a high probability of shock or a pre-shock state, hypoxic gas ventilation therapy was initiated at thispoint. The period between admission and initiation of hypoxic gas ventilation therapy was $1.2 \pm$ 1.0 days. The period of hypoxic gas ventilation therapy (the period between therapy initiation and surgery) was $4.5 \pm$ 1.5 days. The value of $\mathrm{FiO}_{2}$ (the fraction of inspired oxygen in a gas mixture) was set to between $14 \%$ and $19 \%$ based on previous clinical experience. ${ }^{9}$

The nitrogen gas mixture used for hypoxic gas ventilation was administered via a nasal cannula in 6 patients and under tracheal intubation in 2 patients. Barbituric acid (Phenobarbital, Wako-do, Tokyo, 4-7 mg $\cdot \mathrm{kg}^{-1} \cdot \mathrm{day}^{-1}$ ) and chloral hydrate (tricloryl syrup; Alfresa pharma, Osaka; 0.7$1.0 \mathrm{ml} / \mathrm{kg}$ once or twice a day) were administered for sedation as required. A V.I.P Bird ventilator (Birds Products Co, Dublin, OH, USA) was used for the intubated patients, and the ventilation mode was an Assist-Control. No muscle relaxant was administered, and spontaneous respiration was allowed. Hypoxic gas ventilation therapy was administered in accordance with the protocol formulated by a research team from the Ministry of Health, Labour and Welfare of Japan. ${ }^{32}$ The $\mathrm{FiO}_{2}$ was measured directly at the outlet of the ventilator circuit in infants who were intubated or who were on an artificial respirator. In the patients in whom a nasal cannula were used for hypoxic gas ventilation therapy, the value that was calculated from the mixture fractions of atmospheric air and nitrogen gas was regarded as the $\mathrm{FiO}_{2}$. The study protocol included that blood collection, measurement of vital signs and ultrasound heart and brain echo-graphic examination was performed at $30 \mathrm{~min}$ before hypoxic gas ventilation therapy, and at $30 \mathrm{~min}, 1 \mathrm{~h}, 6 \mathrm{~h}, 12 \mathrm{~h}$, and $24 \mathrm{~h}$ after hypoxic gas ventilation therapy was started. During the therapy, blood was collected as mentioned above in order to measure the $\mathrm{pH}, \mathrm{pCO}_{2}$ base excess, and lactic acid levels. 


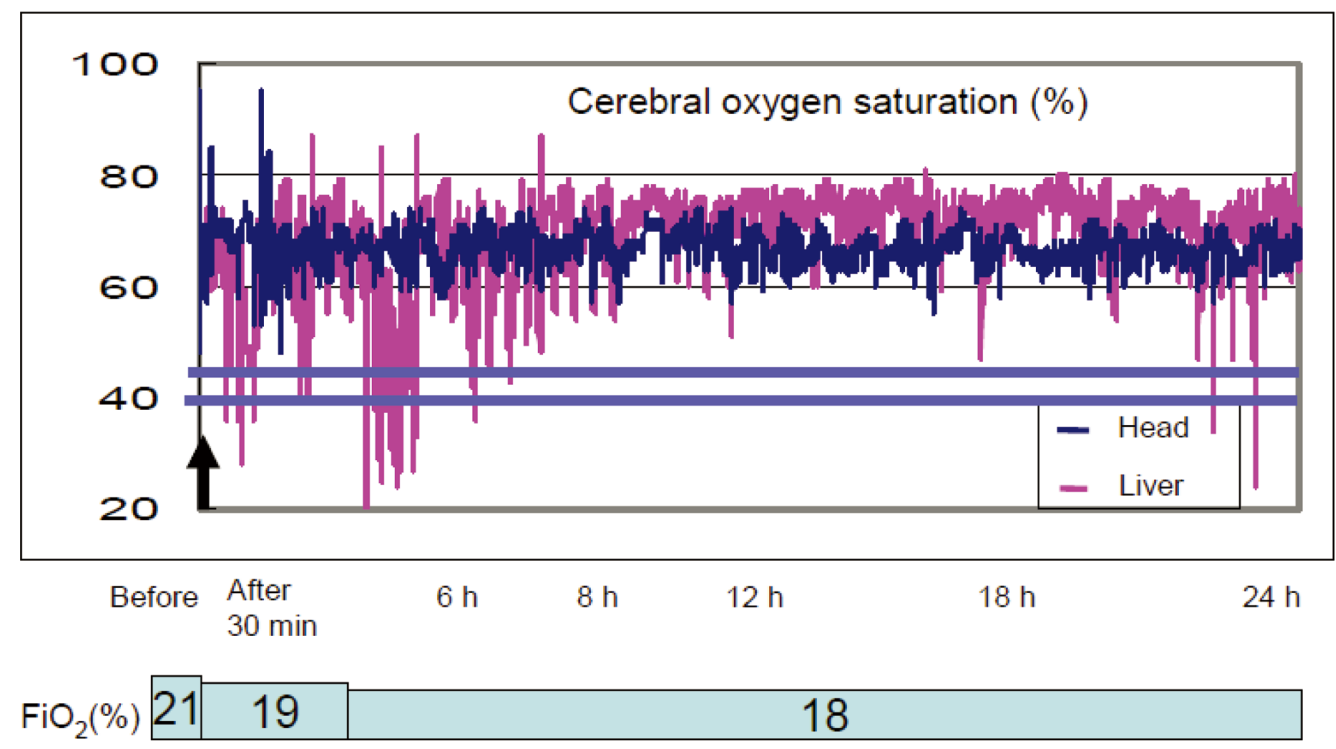

Figure 1. A record of the cerebral oxygen saturation in a patient (case 7) having hypoplastic left heart syndrome with mitral atresia and aortic atresia, and with the oxygen saturation within the tissues of the abdomen (liver) measured as the control. The record is partially disordered because of body motion.

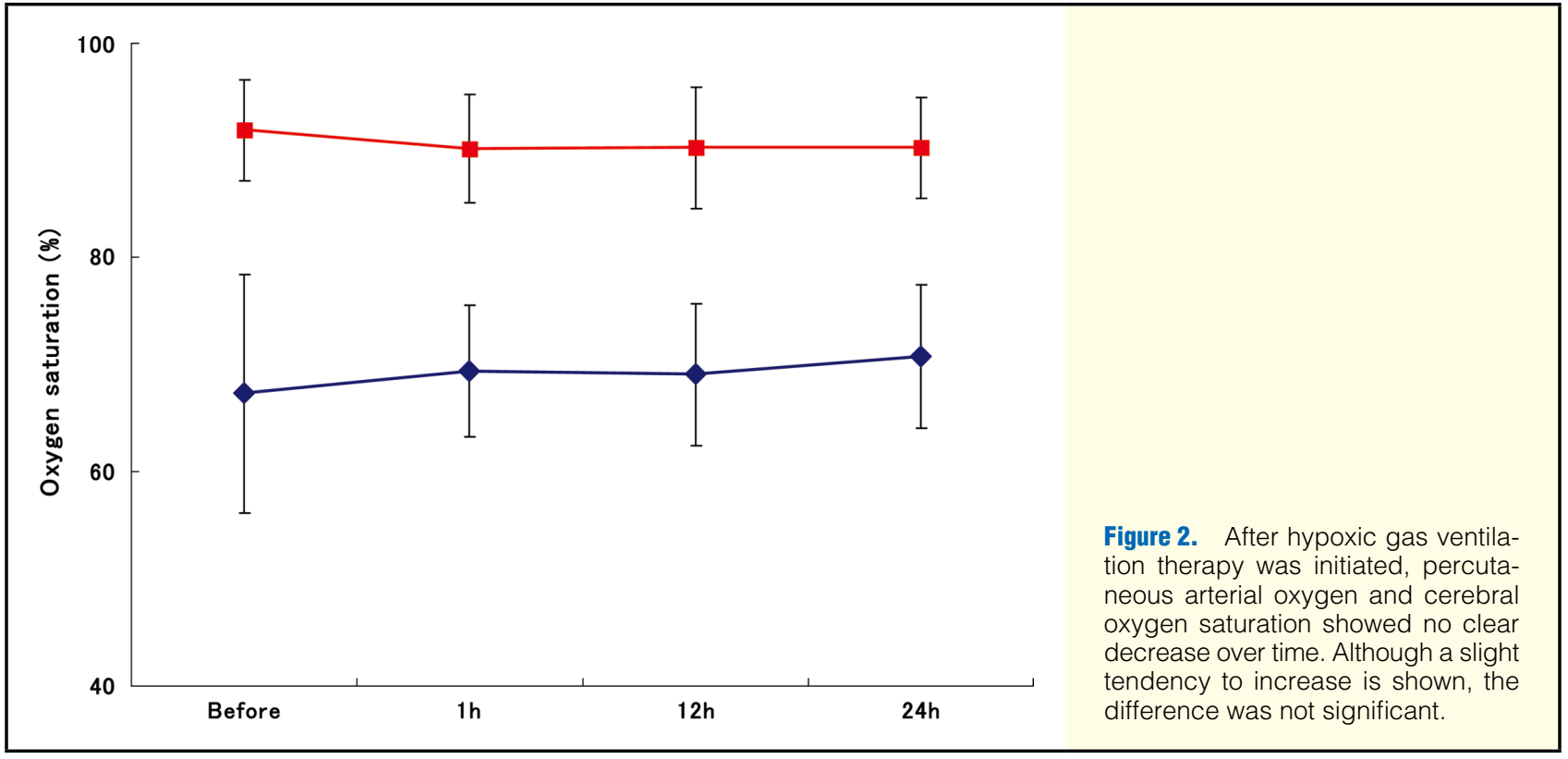

A systemic blood pressure, heart rate, urinary volume an hour, and $\mathrm{SpO}_{2}$, ware measured as major vital signs. Cerebral regional oxygen saturation (cerebral $\mathrm{rSO}_{2}$ ) was measured using an INVOS 5100 near-infrared spectroscope (NIRS; Edwards Lifesciences, Irvine, CA, USA). ${ }^{10-12}$ A pediatric sensor of INVOS 5100 had been put on the right side of the forehead as much as possible. A cerebral ultrasound echo-graphic examination was performed simultaneously to measure the resistance index (RI), an index of vascular resistance. ${ }^{13-15}$ The RI, expressed as (systolic blood flow velocity-diastolic blood flow velocity)/(systolic blood flow velocity), mainly indicates a change in intracranial status, but it is used for the diagnostic assistance of intracranial circulation. ${ }^{29,30}$ Changes in the middle cerebral artery (MCA) blood flow pattern and the RI were studied in order to determine whether cerebral blood flow, that is, cerebral tissue oxygen supply, would improve with therapy. In addition, hepatic $\mathrm{rSO}_{2}$ was measured in the same patients as a control because hepatic blood flow is almost stable under systemic stable condition. ${ }^{31}$ This study was performed in accordance with the rules and regulations for clinical research at Kyoto Prefectural University of Medicine. The nature of this study was discussed with the parents of each patient, and written informed consent for the study protocol was obtained before initiating hypoxic gas 

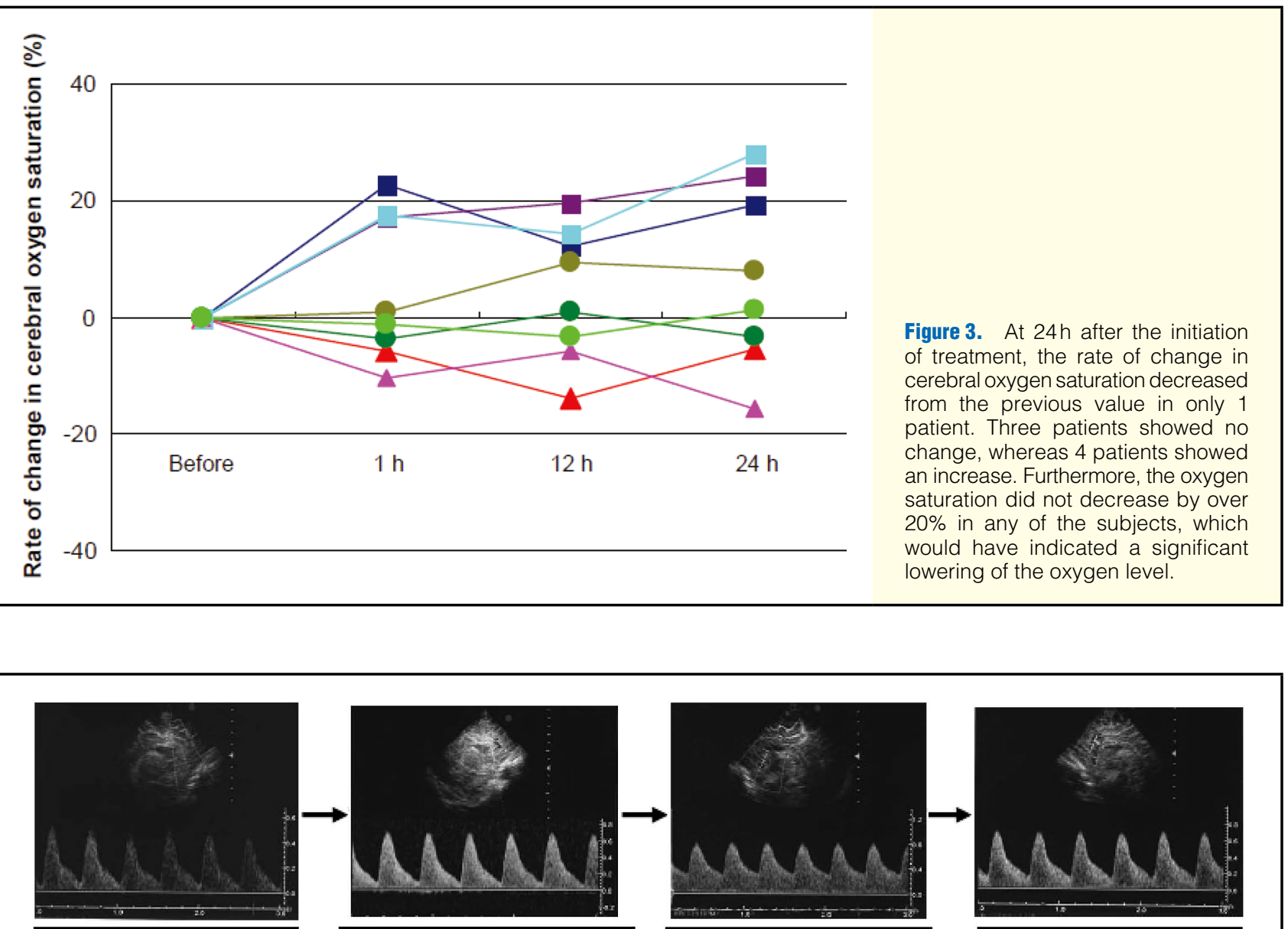

Before the initiation of $\mathrm{N}_{2}$

Figure 4. Changes in the middle cerebral artery blood flow pattern based on a head echo-gram obtained during hypoxic gas ventilation therapy. Although the diastolic blood flow velocity was low before the treatment, the diastolic blood flow velocity increased significantly.

ventilation therapy. Statistical analysis was conducted using a paired t-test, and $\mathrm{P}<0.05$ was considered statistically significant.

\section{Results}

The results of hypoxic gas ventilation therapy are summarized in Table. The urinary volume an hour increased $(\mathrm{P}<0.05)$ from $2.2 \pm 1.0 \mathrm{ml} \cdot \mathrm{kg}^{-1} \cdot \mathrm{h}^{-1}$ before to $3.5 \pm 0.8 \mathrm{ml}$. $\mathrm{kg}^{-1} \cdot \mathrm{h}^{-1}$ at $12 \mathrm{~h}$ after the initiation of treatment. The respiratory rate showed a clear decrease $(\mathrm{P}<0.05)$ from $79.0 \pm$ 15.6 breaths $/ \mathrm{min}$ before to $55.6 \pm 9.3 \mathrm{breaths} / \mathrm{min}$ at $12 \mathrm{~h}$ after the initiation of treatment. The $\mathrm{SpO}_{2}$ before and $12 \mathrm{~h}$ after the initiation of treatment was $91.9 \pm 4.6 \%$ and $90.3 \pm 4.7 \%$, respectively; a difference that was not significant (Figure 2). Other parameters such as blood $\mathrm{pH}, \mathrm{pCO}_{2}$, base excess, lactic acid and systemic blood pressure did not deteriorate. None of the patients in this study were suffering from a critical condition such as heart failure, shock or systemic hypotension during hypoxic gas ventilation therapy, and all of the patients in this study were in a better condition after their first scheduled operation compared to their status before hypoxic gas ventilation.
The average cerebral $\mathrm{rSO}_{2}$ was $67.3 \pm 11.1 \%$ before the initiation of hypoxic gas ventilation therapy, and this increased to $69.4 \pm 6.1 \%, 69.1 \pm 6.6 \%$, and $70.7 \pm 6.7 \%$ (not significant) within 1,12 , and $24 \mathrm{~h}$ after the initiation of treatment, respectively, and there was no decrease during the follow-up period (Figure 2). In addition, a study of the rate of percentage change of the post-treatment (post hypoxic gas ventilation) cerebral $\mathrm{rSO}_{2}$, as compared with the pre-treatment value, revealed that 3 of the 8 patients showed no change, whereas a clear increase was observed in the other 4 patients. Only 1 patient had a decreased cerebral $\mathrm{rSO}_{2}$ from $79 \%$ to $67 \%$, and it was a $15 \%$ decrease compared with the pre-treatment cerebral $\mathrm{rSO}_{2}$ (Figure 3). Consequently, none of the 8 patients showed a critical decrease of $20 \%$ or more in cerebral $\mathrm{rSO}_{2}$. Furthermore, none of the patients showed a cerebral $\mathrm{rSO}_{2}$ of $40 \%$ or less, which is regarded as the point of initiation of anaerobic metabolism, or $44 \%$ or less, which is regarded as being associated with hypoxic-ischemic nervous damage. A MCA blood flow pattern (Figure 4) showed a clear increase in the diastolic blood flow, and the RI indicated a significant improvement in the blood flow pattern from $0.80 \pm 0.15$ before treatment to $0.68 \pm 0.14$ within $12 \mathrm{~h}$ after the initiation of treatment (Figure 5). 


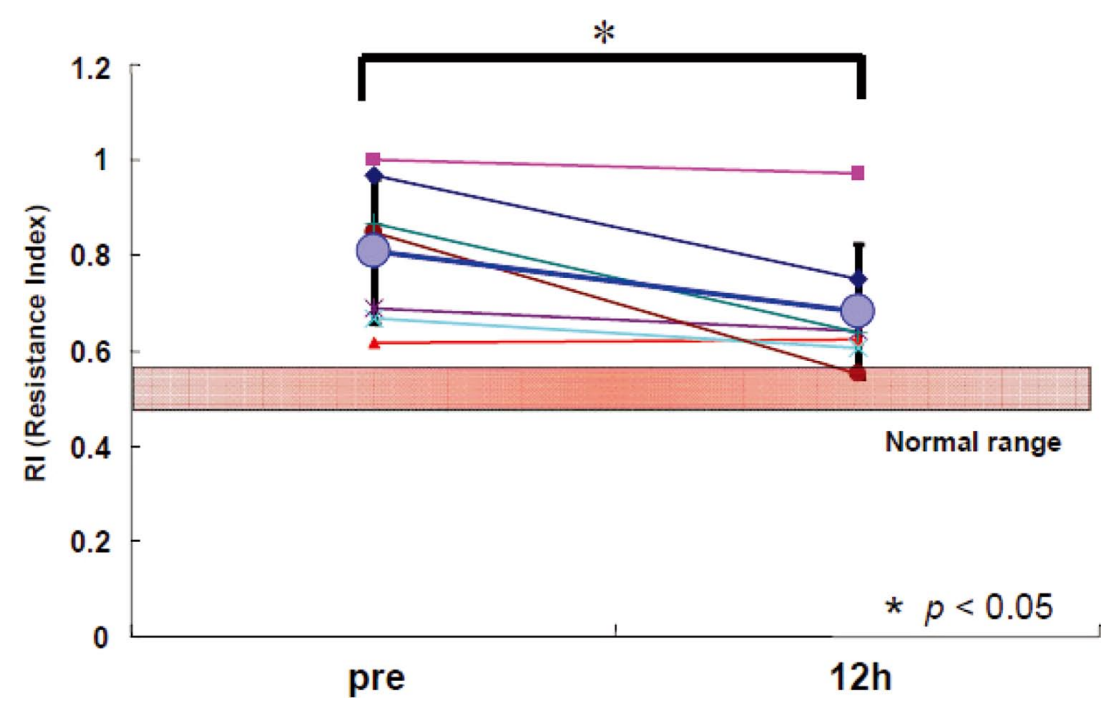

Figure 5. Changes of the resistance index (RI), before and after the treatment. Hypoxic gas ventilation therapy significantly improved the RI value.

\section{Discussion}

Hypoxic gas ventilation therapy ${ }^{5-8}$ is a treatment method in which nitrogen gas is mixed with air to artificially decrease the $\mathrm{FiO}_{2}$ to less than $21 \%$. This inhaled oxygen content decrease induces hypoxic vasoconstriction, ${ }^{21-23}$ and results in an increase in pulmonary vascular resistance. According to a report by Reddy et al, ${ }^{24}$ when a sheep inhaled hypoxic gas $\left(10 \% \mathrm{FiO}_{2}\right)$ after a main artery to pulmonary artery shunt had been created, the pulmonary vascular resistance increased significantly, whereas the pulmonary blood flow and the pulmonary-to-systemic blood flow ratio decreased significantly. On the basis of this evidence, hypoxic gas ventilation therapy was first applied to the preoperative management of HLHS and its clinical efficacy was assessed.5, ${ }^{5}$ It has subsequently been widely applied in clinical practice throughout the world. In 1999, we also administered hypoxic gas ventilation therapy to 4 patients with HLHS, and ascertained the clinical efficacy thereafter. ${ }^{9}$ We have previously reported that the $\mathrm{SaO}_{2}$ decreases with the inhalation of hypoxic gas. However, tissue oxygen supply was comparatively higher during hypoxic gas ventilation therapy because the pulmonary vascular resistance increased and therefore the systemic circulation also increased, as indicated that at these $\mathrm{FiO}_{2}$ levels; $\mathrm{SaO}_{2}$ of the lower part of the body remains stable at approximately $80 \%$, a sufficient urinary volume is assured, and preoperative circulatory dynamics can be managed stably. ${ }^{9}$

Recently, hypoxic gas ventilation therapy has commonly been administered to patients with congenital heart diseases at some children's hospital in Japan ${ }^{7,9,35}$ who have increased pulmonary blood flow, and it has provided excellent results. In our study, the respiratory rate after the initiation of treatment decreased in all study patients. Furthermore, as stated in other reports, an increase in the urinary volume was also observed, ${ }^{5,7,9}$ and all preoperative circulatory dynamics were improved. In the present study, an increased urinary volume, using the method described above, might have resulted in the increased renal blood flow that has been reported previously. $5,7,9$ It is thought that pulmonary vascular resistance increases, causing a decrease in blood drawn into the lungs., 5,9 Thus, the blood circulating systemically increases, resulting in an increased renal blood flow and urinary volume.
In contrast, a decrease in tissue oxygen supply was previously a matter of concern with regard to hypoxic gas ventilation therapy. In particular, low oxygen supply to the brain during the growth phase might cause irreversible sequelae on the subsequent growth and development of a patient. In general, the tissue oxygen supply is calculated as a product of the oxygen flow rate and systemic blood flow. ${ }^{25}$ During hypoxic gas ventilation therapy, the oxygen flow rate decreases, whereas systemic blood flow increases; hence, it is important to determine whether the oxygen supply to the tissues would eventually increase or decrease. We recently reported that the systemic circulation increases during hypoxic gas ventilation therapy, thereby causing an increase in the oxygen supply to the tissues. ${ }^{9}$

Cerebral tissue oxygen saturation monitored by NIRS has been applied in surgery, mainly for extracorporeal circulation, as a highly practical real-time measurement technique with an excellent level of simplicity, non-invasiveness, and continuity. ${ }^{19,27}$ The results of this study were obtained by direct continuous measurement of cerebral $\mathrm{rSO}_{2}$, starting from before the initiation of treatment. By studying the changes in these values for a relatively longer period, we consider our observations to be more practically relevant. The cerebral $\mathrm{rSO}_{2}$ of adults varies over a wide range from $45 \%$ to $85 \% .^{12}$ It is thought that the cerebral $\mathrm{rSO}_{2}$ values for children are similar to those of adults, ${ }^{28}$ and that lower values are not associated with neurological sequelae, ${ }^{16}$ particularly for cyanotic congenital heart disease. However, it is difficult to determine ischemia and other such changes based on the absolute cerebral $\mathrm{rSO}_{2}$ value. ${ }^{33,34}$ It is clinically common to determine a change in the oxygen supply to the cerebral tissues using a change in cerebral $\mathrm{rSO}_{2}$ from the baseline, which is the cerebral $\mathrm{rSO}_{2}$ before treatment. In most cases, when the baseline value decreases by at least $20 \%$ or the absolute value decreases to $40 \%$ or less, there is a high probability that the oxygen supply has decreased. ${ }^{17-19}$ Furthermore, the results of animal and in vitro experiments indicate that anaerobic metabolism begins when the $\mathrm{rSO}_{2}$ of the tissues decreases to $40 \%$ or less. ${ }^{19,20}$ In this study, the lower limit of cerebral $\mathrm{rSO}_{2}$ was set at $40 \%$, and the cerebral $\mathrm{rSO}_{2}$ was measured continuously for $24 \mathrm{~h}$ from the initiation of hypoxic gas ventilation therapy (Figure 1). 
Furthermore, in addition to changes in cerebral oxygen saturation, we simultaneously assessed changes in the RI by measuring the MCA blood flow pattern. The visualization of this MCA blood flow pattern allowed us to capture changes in hemodynamics, and we thus believe it to be an effective assessment method. The blood flow pattern in normal cerebral blood vessels ${ }^{13-15}$ increases during systole and continues during diastole; hence, it is similar to the blood flow pattern in a patient with PDA. Because it is an index obtained by measuring blood flow velocity, the RI is high in patients with PDA, a condition in which the diastolic blood flow is generally drawn into the lungs. However, because of the difference in compliance between the lung and systemic vascular beds, blood is drawn from the systemic to the pulmonary circulation during diastole, resulting in regurgitation. With regard to the blood flow pattern in the MCA, blood was similarly drawn before the initiation of hypoxic gas ventilation therapy until the diastolic blood flow velocity became almost zero, and the blood flow ceased in many of the patients. It is thought that hypoxic gas ventilation was initiated to increase the pulmonary vascular resistance in this state; thus, the gap in compliance between the lung and systemic vascular beds during the diastole was filled, thereby resulting in a decrease in blood flowing into the lungs, which improved the RI.

In future, we will increase the number of each case to examine the details why there is no difference between HLHS group whose cerebral blood flow is dependent on PDA and IAA/CoA complex group whose cerebral blood flow is not dependent on PDA.

\section{Conclusions}

In this study, the results indicated that hypoxic gas ventilation therapy in patients with HLHS, IAA/CoA complex with increased pulmonary blood flow does not cause a critical hypoxia in the cerebral circulation, but it does improve the blood flow pattern in the MCA and the cerebral tissue blood supply. Accordingly, it is believed that hypoxic gas ventilation therapy would not affect the central nervous system and could be performed safely in patients with HLHS or IAA/ CoA complex, in which PDA is dependent for systemic circulation.

\section{Acknowledgments}

This study was supported, in part, by a grant (17 Public-5) from the Ministry of Health, Labour and Welfare of Japan.

\section{References}

1. Terai M, Niwa K, Nakazawa M. Mortality from congenital cardiovascular malformations in Japan, 1968 Through 1997. Circ J 2002; 66: $484-488$

2. Norwood WI Jr. Hypoplastic left heart syndrome. Ann Thorac Surg 1991; 52: 688-695.

3. Jobes DR, Nicolson SC, Steven JM, Miller M, Jacobs ML, Norwood WI Jr. Carbon dioxide prevents pulmonary overcirculation in hypoplastic left heart syndrome. Ann Thorac Surg 1992; 54: 150-151.

4. Mora GA, Pizarro C, Jacobs ML, Norwood WI. Experimental model of single ventricle: Influence of carbon dioxide on pulmonary vascular dynamics. Circulation 1994; 90: 1143-1146.

5. Day RW, Barton AJ, Pysher TJ, Shaddy RE. Pulmonary vascular resistance of children treated with nitrogen during early infancy. Ann Thorac Surg 1998; 65: 1400-1404.

6. Emery JR. Strategies for prolonged survival before heart transplantation in the neonatal intensive care unit. J Heart Lung Transplant 1993; 12: S161-S163.

7. Park IS, Yamamura H, Sasaki Y, Yokoyama U, Nakanishi T, Nakazawa M, et al. Supplemental nitrogen therapy in infants with congenital heart defects and increased pulmonary blood flow (in
Japanese). Jpn J Pediatr Cardiol Cardiac Surg 2000; 16: 869-876.

8. Shime N, Hashimoto S, Hiramatsu N, Oka T, Kageyama K, Tanaka Y. Hypoxic gas therapy using nitrogen in the preoperative management of neonates with hypoplastic left heart syndrome. Pediatr Crit Care Med 2000; 1: 38-41.

9. Oka T, Itoi T, Kawai A, Toiyama K, Sato H, Ozawa S, et al. Effects of hypoxia inhalation therapy using nitrogen gas mixture on infants with hypoplastic left heart syndrome. Jpn J Pediatr Cardiol Cardiac Surg 2003; 19: 2-7 (in Japanese).

10. Kirkpatrick PJ, Smielewski P, Whitfield PC, Czosnyka M, Menon D, Pickard JD. An observational study of near-infrared spectroscopy during carotid endarterectomy. J Neurosurg 1995; 82: 756-763.

11. Kirkpatrick PJ, Smielewski P, Czosnyka M, Menon DK, Pickard JD. Near-infrared spectroscopy use in patients with head injury. J Neurosurg 1995; 83: 963-970.

12. Katoh T, Esato K, Gohra H, Hamano K, Fujimura Y, Zempo N, et al. Evaluation of brain oxygenation during selective cerebral perfusion by near-infrared spectroscopy. Ann Thorac Surg 1997; 64: $432-436$.

13. Lindegaard KF, Lundar T, Wiberg J, Sjoberg D, Aaslid R, Nornes $H$. Variations in middle cerebral artery blood flow investigated with noninvasive transcranial blood flow velocity measurements. Stroke 1987; 18: $1025-1030$.

14. Weyland A, Stephan H, Kazmaier S, Weyland W, Schorn B, Grune $\mathrm{F}$, et al. Flow velocity measurements as an index of cerebral blood flow. Anesthesiology 1994; 81: $1401-1410$.

15. Polito A, Ricci Z, Chiara LD, Giorni C, Iacoella C, Sanders SP, et al. Cerebral blood flow during cardiopulmonary bypass in pediatric cardiac surgery: The role of transcranial Doppler-a systemic review of the literature. Cardiovasc Ultrasound 2006; 4: 47.

16. Rubio A, Hakami L, Munch F, Tandler R, Harig F, Weyand M. Noninvasive control of adequate cerebral oxygenation during lowflow antegrade selective cerebral perfusion on adults and infants in the aortic arch surgery. J Card Surg 2008; 23: 474-479.

17. Harvey L, Edmonds HL, Singer I, Sehic A, Strickland TJ. Multimodality neuromonitoring for neurocardiology. J Interv Cardiol 1998; 11: 197-204.

18. Cho H, Nemoto EM, Yonas H, Balzer J, Sclabassi RJ. Cerebral monitoring by means of oximetry and somatosensory evoked potentials during carotid endarterectomy. J Neurosurg 1998; 89: $533-$ 538.

19. Reents W, Muellges W, Franke D, Babin-Ebell J, Elert O. Cerebral oxygen saturation assessed by near-infrared spectroscopy during coronary artery bypass grafting and early post-operative cognitive function. Ann Thorac Surg 2002; 74: 109-114.

20. Kurth CD, Levy WJ, McCann J. Near-infrared spectroscopy cerebral oxygen saturation thresholds for hypoxia-ischemia in piglets. J Cereb Blood Flow Metab 2002; 22: 335-341.

21. Voelkel NF. Mechanisms of hypoxic pulmonary vasoconstriction. Am Rev Respir Dis 1986; 133: 1186- 1195.

22. Penaloza D, Arias-Stella J. The heart and pulmonary circulation at high altitudes: Healthy highlanders and chronic mountain sickness. Circulation 2006; 115: 1132-1146.

23. Blunt SG Jr. Comparison of patients with ventricular septal defect at high altitude and sea level. Circulation 1977; 56(Suppl I): 7982.

24. Reddy VM, Liddicoat JR, Fineman JR, McElhinney DB, Klein JR, Hanley FL. Fetal model of single ventricle physiology: Hemodynamic effects of oxygen, nitric oxide, carbon dioxide, and hypoxia in the early postnatal period. J Thorac Cardiovasc Surg 1996; 112: 437-449.

25. Barnea O, Santamore WP, Rossi A, Salloum E, Chien S, Austin EH. Estimation of oxygen delivery in newborns with a univentricular circulation. Circulation 1998; 98: 1407-1413.

26. Ramamoorthy C, Tabbutt S, Kurth CD, Steven JM, Montenegro LM, Durning S, et al. Effects of inspired hypoxic and hypercapnic gas mixtures on cerebral oxygen saturation in neonates with univentricular heart defects. Anesthesiology 2002; 96: 283-288.

27. Higami T, Kozawa S, Asada T, Obo H, Gan K, Iwahashi K, et al. Retrograde cerebral perfusion versus selective cerebral perfusion as evaluated by cerebral oxygen saturation during aortic arch reconstruction. Ann Thorac Surg 1999; 67: 1091-1096.

28. Torin S, Joseph DT. Cerebral oxygenation monitoring using near infrared spectroscopy during controlled hypotension. Pediatric Anesthesia 2005; 15: 504-508.

29. Pezzati M, Dani C, Biadaioli R, Filippi L, Biagiotti R, Giani T, et al. Early postnatal Doppler assessment of cerebral blood flow velocity in healthy preterm and term infants. Dev Med Child Neurol 2002; 44: $745-752$.

30. Nishimaki S, Seki K, Yokota S. Cerebral blood flow velocity in two 
patients with neonatal cerebral infarction. Pediatr Neurol 2001; 24: $320-323$.

31. Hashimoto K, Murakami T, Dono K. Quantitative tissue blood flow measurement of the liver parenchyma: Comparison between xenon CT and perfusion CT. Dig Dis Sci 2007; 52: 943-949.

32. Ishizawa R. Guidance of hypoxic gas ventilation therapy using a nitrogen gas mixture for congenital heart diseases with markedly increased pulmonary blood flow. Ministry of Health, Labour and Welfare of Japan, 2009 (in Japanese).
33. Koike A, Hoshimoto M, Tajima A. Critical level of cerebral oxygenation during exercise in patients with left ventricular dysfunction. Circ J 2006; 70: 1457-1461.

34. Koike A, Nagayama O, Hoshimoto-Iwamoto M. Clinical significance of cerebral oxygenation during exercise in patients with coronary artery disease. Circ J 2008; 72: 1852-1858.

35. Tan T, Mizobe N, Sugiyama H. Supplemental nitrogen inhalation therapy in very low-birth-weight infants with patent ductus arteriosus. Pediatr Cardiol 2005; 26: 801-804. 